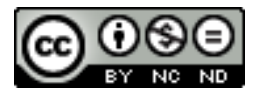

Revista Pax Domini é licenciada sob uma Licença Creative Commons.

\title{
EDUCAÇÃO E A PERSPECTIVA DO ENCONTRO-DIÁLOGO
}

Edeney Barroso Salvador ${ }^{1}$

\begin{abstract}
Resumo
Reflete acerca da educação na perspectiva do encontro-diálogo. Tem como objetivo apresentar as dimensões da educação, delimitada nos aspectos do encontro-diálogo consigo mesmo, com o outro, com o transcendente e com a natureza, a fim de somar positivamente no debate acerca dos desafios das práxis educativas, tendo em conta as diversidades. O texto nasce de uma inquietação pessoal, ao constatar, no cotidiano do fazer/viver educativo e nos seus resultados na vida comum de cidadãos e cidadãs, educadores/as e educandos/as, que a habilidade do encontro-diálogo é pouco desenvolvida, e, portanto, carregada de conflitos a serem superados. O texto-discurso foi construído com base nas leituras e hermenêutica de textos que discutem a educação focada na humanização e libertação da pessoa humana, atento aos aspectos antropoteo-ecológico-culturais. Finalmente, aponta-se para horizontes que possam contribuir no devir de um ensino-aprendizagem consciente das identidades da pessoa humana: dialógica-transcendental-ecológica.
\end{abstract}

Palavras-chave: Educação; Encontro-Diálogo; Transcendência. Natureza

\begin{abstract}
Reflects on education in the perspective of the encounter-dialogue. It aims to present the dimensions of education, delimited in the aspects of the encounter-dialogue with itself, with the other, with the transcendent and with nature, in order to add positively in the debate about the challenges of educational praxis, taking into account the diversities. The text is born of a personal uneasiness, when realizing, in the daily of the educational do / living and its results in the common life of citizens, educators and learners, that the ability of the encounter-dialog is little developed, and, therefore, loaded with conflicts to be overcome. The text-discourse was constructed based on the readings and hermeneutics of texts that discuss education focused on the humanization and liberation of the human person, attentive to the anthropological-ecological-cultural aspects. Finally, it points to horizons that can contribute to the development of a conscious teaching-learning of the identities of the human person: dialogic-transcendental-ecological.
\end{abstract}

Keywords: Education. Meeting-Dialogue; Transcendence; Nature

${ }^{1}$ Doutorando do Programa de Pós-Graduação em Teologia da EST (DINTER - Manaus/AM).

Revista Pax Domini | Faculdade Boas Novas | v. 3 | p. 167 - 175 | ago. 2018 


\section{Introdução}

Ao contemplar as realidades que formam o grande e complexo desenho das sociedades e suas relações, constatamos uma infinidade de elementos que, de acordo com o nosso olhar ou leitura, acabamos por classificar. Alguns classificamos como bons, belos, positivos, de valor, etc.; outros como maus, feios, negativos, sem valor; outros, ainda, como certos ou errados; por fim, alguns chamamos de fatos verdadeiros ou falsos (coisas verdadeiras, coisas falsas). E poderíamos prosseguir com a lista dessas dualidades. Tudo isso para dizer e mostrar que é difícil ter uma visão total e real da realidade, assim como da história humana.

Propomos pensar/refletir a educação que conceba novas relações, rompa com os dualismos e as classificações simplistas, e também abra horizontes fecundos para nos ajudar a ver, respeitar e comungar com as diferenças. Em outras palavras, aspiramos por uma educação que contribua à convivência mais humano-solidária e dialógica com as diversidades.

A educação tem um sublime compromisso de proporcionar e provocar o encontrodiálogo entre os indivíduos, ${ }^{2}$ os grupos, as comunidades e os povos. Nesta perspectiva, preocupa-se com as diversas formas de cada povo viver e expressar a sua própria cultura, em uma relação dialógica, ${ }^{3}$ onde não se disputa forças, saberes, técnicas, etc., mas se fazem trocas, intercâmbios e partilha; exercita-se na cooperação de um desenvolvimento mútuo necessário. ${ }^{4}$ Porém, isto não nos isenta do conflito, e o diálogo

\footnotetext{
2 "Não é possível sermos completamente felizes numa sociedade onde os outros não o são. Respeitar as necessidades coletivas não é aniquilar as individualidades, as histórias pessoais. O coletivo se constrói com identidades diferentes, onde cada um tem o direito de ser o que é e desse jeito complementa o conjunto. A Educação padronizada nem desenvolve o potencial individual nem contribui para 0 enriquecimento da construção coletiva". - Cf. CONFERÊNCIA NACIONAL DOS BISPOS DO BRASIL, Campanha da Fraternidade - 1998, Fraternidade e Educação - A serviço da vida e da esperança, TEXTOBASE, 2. ed. São Paulo: Salesiana Dom Bosco, n 89.

3 "[...] O diálogo sincero supõe, por um lado, aceitar reciprocamente a existência das diferenças, ou também as contradições, e, pelo outro, respeitar a livre decisão que as pessoas tomam em conformidade com a própria consciência". - Cf. Diálogo e Anúncio, 1996, 40 e 41, do Pontifício Conselho para o Diálogo InterReligioso.

4 "Un desarrollo centrado en el ser humano, finalidad de la educación y de la cultura". Cf. NANZHAO, Zhou. in: La educación encierra un tesoro - Informe a la UNESCO de la comisión Internacional sobre la educación para el siglo XXI, presidida por JACQUES DELORS, Santillana Ediciones UNESCO, 1996, p. 294. Disponível em:< http://ceups.educacion.unmsm.edu.pe/proyeccion archivos/educacion-encierra-untesoro.pdf>. Acessado em:29 ago. 2016.
}

Revista Pax Domini | Faculdade Boas Novas | v. 3 | p. 167 - 175 | ago. 2018 
nos coloca nesta condição ${ }^{5}$. O encontro entre pessoas, povos e o convívio com a diversidade, sempre foi, é, e será um meio por excelência de aprendermos que o mundo é muito mais do que simplesmente o que a nossa percepção, opinião, pensamento e educação alcançam. O encontro é a superação da fronteira do etnocentrismo, ${ }^{6}$ esse que impede de ver, no outro e na outra, a riqueza da diversidade (de cores, gostos, estéticas, pensamentos, modos de agir, acreditar, etc.).

\section{Educação para o encontro-diálogo consigo mesmo}

Todo o conjunto daquilo que chamamos de educação é um projeto/espaço que pretende contribuir na formação da pessoa humana na sua integralidade. Proporcionar às pessoas um aprendizado da relação consigo mesmas é um ganho neste aspecto. Porém, essa relação não pode ser alheia à história, descontextualizada das outras

relações. É, portanto uma relação que parte do eu-autônomo/a e que se constrói na proximidade com o outro e com a outra7.

Cada pessoa é convidada a confrontar-se com a sua própria história e tomar consciência de todo o universo de coisas que a constitui, isto é, com tudo aquilo que ela foi (fruto de um passado), é (presente), e será (projeções de futuro); é o olhar, a descoberta, o aprender a respeito dos elementos que a constituem como pessoa humana, e decidir livremente seu modus vivendi, não esquecendo o respeito mútuo entre seus pares. Desse modo, aperfeiçoa-se a autonomia educativa, e amplia suas relações. ${ }^{8}$

\footnotetext{
${ }^{5}$ Moacir Gadotti, Paulo Freire e Sérgio Guimarães, no prefácio à 4⿳亠丷a edição da obra pedagogia: diálogo e conflito sustentam "[...] que o diálogo se dá entre iguais e diferentes, nunca entre antagônicos. Entre esses, no máximo pode haver um pacto. Entre esses há é o conflito, de natureza contrária ao conflito existente entre iguais e diferentes". Cf. GADOTT, Moacir; FREIRE, Paulo; GUIMARÃES, Sérgio. Pedagogia: diálogo e conflito. 4 ed. - São Paulo: Cortez, 1995.

${ }^{6}$ Cf. ROCHA, Everardo P. Guimarães. O que é Etnocentrismo. 11. Ed São Paulo: Brasiliense. p. 93: "A ida ao 'outro' se faz alternativa para o 'eu'. O plano onde as diferenças se encontram, onde o 'eu' e o 'outro' se podem olhar como iguais, onde a comparação se traduz num enriquecimento de possibilidades existenciais, é o plano mais amplo de um humanismo do qual o etnocentrismo se ausenta".

7 J. DELORS, 1996, p. 18, em seu artigo La educación o la utopía necesaria, como introdução ao Informe a UNESCO, La educación encierra un tesoro, pensa educação como algo que deve ajudar o indivíduo a expandir-se, quando afirma: "La educación tiene la misión de permitir a todos sin excepción hacer fructificar todos sus talentos y todas sus capacidades de creación, lo que implica que cada uno pueda responsabilizarse de símismo y realizar su proyecto personal.".

${ }^{8}$ Vale ressaltar aqui de novo a contribuição da CNBB quanto à ideia do processo de educação, de como e quando acontece: "[...] A educação acontece de forma permanente, desde o ventre materno,
}

Revista Pax Domini | Faculdade Boas Novas | v. 3 | p. 167 - 175 | ago. 2018 
Mas, para isso é necessário que lhe seja favorecido instrumentos adequados, a fim de poder realizar tal tarefa, em vista de uma autonomia. ${ }^{9} \mathrm{O}$ encontro-diálogo consigo mesmo não é um ensimesmamento, ao contrário, leva ao encontro e à descoberta do/a outro/a, e, consequentemente, a uma comunhão com tudo o que nos rodeia. ${ }^{10} \mathrm{Em}$ outros termos, esta descoberta pessoal é um alargamento do potencial humano, e se afirma no encontro-diálogo com o/a outro/a. Sobre isto, refletiremos a seguir.

\section{Educação para o encontro-diálogo com o (a) outro (a)}

A pessoa humana é, por excelência, um ser de/para a relação, e disso decorre o seu desenvolvimento e a elaboração de sua identidade familiar, comunitária e de pertença a uma nação-povo-cultura. ${ }^{11}$ Sabemos da Antropologia Teológica que a pessoa humana, imagem e semelhança de Deus ${ }^{12}$, é um ser criado e estimulado para a relação, e é estruturalmente vocacionado ao encontro-diálogo com o seu criador (sua origem), com as outras criaturas e com o/a seu/sua próximo/a. Por conseguinte, educar para o encontro-diálogo é proporcionar ao ser humano, um constante contato e comunhão com a sua origem, onde ele encontra sentido e significado de/para sua existência.

desenvolvendo a capacidade física, psíquica, espiritual, social, intelectual e moral das pessoas. Nesse processo, o ser humano vai se realizando em quatro relações básicas: com o mundo, com os demais seres humanos, consigo mesmo e com Deus" - Cf. CONFERÊNCIA NACIONAL DOS BISPOS DO BRASIL, 1998. $n^{\circ} 88$.

9 "Todos los seres humanos deben estar en condiciones, en particular gracias a la educación recibida en su juventud, de dotarse de un pensamiento autónomo y crítico y de elaborar um juicio propio, para determinar por sí mismos qué deben hacer en las diferentes circunstancias de la vida".Cf. UNESCO, p. 106.

10 Afirma o Informe da UNESCO, p. 104-105: "El descubrimiento del otro pasa forzosamente por el conocimiento de uno mismo; por consiguiente, para desarrollar en el niño y el adolescente uma visión cabal del mundo, la educación, tanto si la imparte la familia como si la imparte la comunidad o la escuela, primero debe hacerle descubrir quién es. Sólo entonces podrá realmente ponerse en el lugar de los demás y comprender sus reacciones."

11. "[...] Toda forma de identidad es de hecho compleja, porque cada individuo se define em relación con el otro, con los otros y con varios grupos de pertenencia, según modalidades dinámicas. El descubrimiento de la multiplicidad de estas pertenencias, más allá de los grupos más o menos reducidos que constituyen la familia, la comunidad local e inclusive la comunidade nacional, conduce a la búsqueda de valores comunes adecuados para establecer la 'solidaridad intelectual y moral dela humanidad"'. Cf. UNESCO, p. $52-53$.

12 Sobre o tema da imagem ver: IAMMARRONE, Giovanni. L'uomo immagine di Dio - Antropologia e Cristologia. Roma: Ed. Borla, 1989; LADARIA, Luiz F. Introduzione all'Antropologia Teologica, 7. ed, 8 IDT, Roma: Ed. Piemme, 1997, cap. III: “L'uomo Immagine di Dio”.

Revista Pax Domini | Faculdade Boas Novas | v. 3 | p. 167 - 175 | ago. 2018 
Educar para o encontro-diálogo com o/a outro/a, visto sob a ótica antropo-social, leva-nos a pensar nos ganhos que esse horizonte favorece a pessoa, como sujeito de sua própria formação. Primeiro, o encontro é algo que põe a pessoa na relação consigo mesma; segundo, essa relação possibilita o intercâmbio e o aprendizado de/sobre outras culturas, e da diversidade. ${ }^{13} \mathrm{E}$, ainda, educa para 0 diálogo e comunhão com as realidades que completam e integram a pessoa humana na compreensão do mundo, dos/das outro/as e de si mesmo. ${ }^{14}$

A educação que se pensa para o encontro-diálogo motiva a pessoa humana a sair do seu próprio mundo, às vezes pequeno e ensimesmado; sair de suas fronteiras, por vezes rígidas, e sair, igualmente, de seu grupo preferido, que pode ser seletivo e infrutífero. Portanto, este horizonte educativo produz uma espécie de extroversão libertadora, e faz com que o outro, a outra sejam vistos/as como uma porta de acesso ao desenvolvimento pessoal e sócio-comunitário.

\section{Educação para o encontro-diálogo com o Transcendente}

Esta é uma tarefa delicada e ao mesmo tempo bela a ser realizada no âmbito da educação. Torna-se ainda mais delicada em nossa contemporaneidade, por vivermos envoltos em estruturas acentuadamente tecnificadas, e com múltiplas expressões religiosas (diferentes "lógicas religiosas"). Além disso, os espaços educacionais ainda são pouco arrojados em proporcionar aos/às educandos/as horizontes para uma real e significativa experiência pessoal e comunitária com o transcendente em suas vidas. A dimensão transcendental da educação não se reduz a uma simples recitação de orações, leituras de textos religiosos, músicas sentimentais, etc. Pensar o transcendental dessa forma é reduzir tal dimensão da pessoa humana a algo sem dinamismo e criatividade, desconexo da vida, e sem vida. O encontro-diálogo com o transcendente é uma

13 "[...] la educación debe asumir la difícil tarea de transformar la diversidad en un fator positivo de entendimiento mutuo entre los individuos y los grupos humanos. Su más alta ambición es brindar a cada cual los medios de una ciudadanía consciente y activa, cuya plena realización sólo puede lograrse en el contexto de sociedades democráticas." Cf. UNESCO, p. 56.

14 "[...] Al permitir a todos el acceso al conocimiento, la educación tiene un papel muy concreto que desempeñar en la realización de esta tarea universal: ayudar a comprender el mundo y a comprender a los demás, para comprenderse mejor a símismo.". Cf. UNESCO, p. 54.

Revista Pax Domini | Faculdade Boas Novas | v. 3 | p. 167 - 175 | ago. 2018 
experiência mística-espiritual (de espiritualidade), ${ }^{15}$ que possibilita à pessoa um engajamento cidadão por mais humanidade nas relações do cotidiano da vida.

No âmbito da educação moderno-contemporânea, constata-se uma bateria de documentos (escritos diversos) que tratam com muita maestria e clareza acerca de propostas para e por uma educação integral, ainda atrelada a uma rígida disciplinaridade - e hoje já se fala, inclusive, de uma educação "rizomática" 16_. Todavia, não basta ter isso claro nos documentos, na filosofia da escola/universidade ou no currículo global de ensino. É imperativo dispor também educadores/as motivados/as, preparados/as e envolvidos com essa realidade, ou pelo menos abertos/as a ela.

O encontro-diálogo com o transcendente não acontece desconectado da experiência pessoal, da história ou do contexto onde se vive; esse encontro se dá no agora, no cotidiano das experiências humanas. Portanto, educar para a relação com o transcendente é possibilitar ao indivíduo fazer a experiência da descoberta e do cultivo desta dimensão (ESPIRITUALIDADE), ${ }^{17}$ e proporcionar-Ihe meios para que ele/ela possa "se ver" internamente e integralmente, contemplar a si mesmo e ao/a outro/a, as coisas, o mundo, a natureza, a arte, a beleza... Com o olhar verdadeiramente humano, criativo e generoso.

\section{Educação para o encontro-diálogo com a natureza}

\footnotetext{
${ }^{15}$ Na perspectiva de Leonardo Boff, a "espiritualidade e mística pertencem à vida em sua integralidade e em sua sacralidade. Daí nascem o dinamismo da resistência e a permanente vontade de libertação". Cf. BOFF, Leonardo; BETTO, Frei. Mística e Espiritualidade, 4. Ed. Rio de Janeiro: Rocco, 1999. p. 11

${ }^{16}$ Silvio Gallo em seu texto Disciplinaridade e transversalidade, conclui que a tendência da educação disciplinar não responde às exigências de uma educação integral. Concorda com a perspectiva de Deleuse e Guatarri, quando tratam da ideia de rizoma; pensa que essa postura responde melhormente ao que é exigido no fazer educativo do nosso tempo, quando diz: "Uma educação rizomática, [...] abre-se para a multiplicidade, para uma realidade fragmentada e múltipla, sem a necessidade mítica de recuperar uma ligação, uma unidade perdida. Os campos de saberes são tomados como absolutamente abertos; com horizontes, mas sem fronteiras, permitindo trânsitos inusitados e insuspeitados". Cf. GALLO, Silvio. Disciplinaridade e transversalidade. In. Linguagens, espaços e tempos no ensinar e aprender. Unicamp e Unimep, 2000. p. 177.

17 "Não devemos nunca esquecer que os portadores permanente da espiritualidade são as pessoas consideradas comuns, que viver a retidão da vida, o sentido da solidariedade, e cultivam o espaço sagrado do Espírito, seja em suas religiões e igrejas, seja no modo como pensam, agem e interpretam a vida". Cf. BOFF, Leonardo. Espiritualidade: um caminho de transformação. Rio de Janeiro: Sextante, 2001. p. 13.
}

Revista Pax Domini | Faculdade Boas Novas | v. 3 | p. 167 - 175 | ago. 2018 
Do ponto de vista de estruturas para atender as necessidades educacionais das pessoas relativas ao domínio da técnica, do cálculo, da informática, da eletrônica, de fórmulas, regras, tabelas e de coisas deste gênero, os espaços educativos, em geral, têm dado um salto quantitativo e qualitativo. Mas, há muito a ser melhorado, inclusive no que diz respeito à inclusão de mais pessoas ao usufruto desses direitos. Por outro lado, percebe-se uma lacuna de instrumentos e de pessoas suficientemente conscientes e motivadas a criar novos meios e técnicas que garantam uma educação de/para a comunhão-interação com a natureza/ecossistemas ${ }^{18}$, em vez do domínio e da pura exploração irracional ${ }^{19}$.

Urge que trabalhemos no despertar e no engajamento das novas gerações, educandos/as, a sensibilidade para o encontro-diálogo com a natureza. Isto implica em garantir e aperfeiçoar uma educação ecológica ${ }^{20}$. A relação-diálogo com a natureza é um exercício responsável pela preservação das vidas. Para aprofundar esta relação, faz-se necessário criar mais espaços de diálogos e aprendizados pertinentes a esta realidade, como também, articular meios que contribuam à qualidade do viver dos seres humanos e de todos os seres, melhor integrados/as, corresponsáveis com o sistema vida.

\section{Considerações Finais}

Fizemos um percurso pautado na ideia-categoria do encontro-diálogo. Esta categoria nos condicionou a pensar o eu-sujeito que, para existir, necessita do encontro-

\footnotetext{
${ }^{18} \mathrm{Na}$ Carta Encíclica Laudato Sí do Papa Francisco, sobre o Cuidado da Casa Comum, n.202, lê-se um indicativo a um novo modus vivendi, para habitarmos a "casa comum": "Falta a consciência duma origem comum, duma recíproca pertença e dum futuro partilhado por todos. Esta consciência basilar permitiria o desenvolvimento de novas convicções, atitudes e estilos de vida". Deisponível em: http://www.oas.org/es/sg/casacomun/docs/papa-francesco-enciclica-laudato-si-sp.pdf. Acessado em: 30 ago. 2016.

19 Numa perspectiva holística da educação para o sec. XXI, podemos levar em conta esta outra advertência: "Hay que preservar la ecología del planeta de las destrucciones irreflexivas y de la explotación salvaje y enriquecerla em beneficio de las generaciones que aún no han nacido; hay que promover un modo deconsumo, más equitativo basado en los limites del crecimiento en lugar deen un despilfarro sin tasa.". - Cf. SINGH, Karan. Educar para la sociedad mundial. in: UNESCO, p. 271.

${ }^{20}$ No Documento da CNBB, $n^{\circ} 156$, lê-se acerca da urgência de uma educação ecológica: "É tarefa da educação criar um novo espírito, um pacto com a natureza. Essa nova relação com o planeta deve levar a um desenvolvimento controlado, não predatório, a um cuidado eficiente e amoroso com a saúde da grande casa de todos nós, a uma postura menos arrogante do ser humano em relação às outras criaturas de Deus".
}

Revista Pax Domini | Faculdade Boas Novas | v. 3 | p. 167 - 175 | ago. 2018 
diálogo com o outro, a outra, integra-se com o transcendente e se humaniza no encontrodiálogo com a natureza, o sistema vida. Cada um dos pontos refletidos quis ser um indicativo de alguns horizontes necessários para onde podemos voltar o nosso olhar e reabilitar nossas sensibilidades, a partir da base educativa, onde construímos nossas perspectivas de mundo, de vida, de humanidade. Pensar/refletir a educação no horizonte dialógico é um caminho para fazer deste instrumento o modus faciendi das pessoas, uma relação-diálogo comprometida com a integridade das vidas. A perspectiva do encontrodiálogo no fazer/viver educativo é um caminho - ou rios/igarapés no contexto Amazônico - que indica à diversidade, alerta ao devir, e inspira a trilhar ou desbravar outros ainda não percorridos ou navegados. Portanto, em acordo com o poema de Antonio Machado, Caminante, podemos, desse modo, concluir :

"[...] Caminante, son tus huellas

el camino y nada más;

caminante, no hay camino, se hace camino al andar.

- Al andar se hace camino

y al volver la vista atrás

se ve la senda que nunca

se ha de volver a pisar.

- Caminante no hay camino

sino estelas en la mar [...]"

(Antonio Machado - Poemas XXIX de Provérbios y Cantares)

\section{Referências}

BOFF, Leonardo. Espiritualidade: um caminho de transformação. Rio de Janeiro: Sextante, 2001.

.BETTO, Frei. Mística e espiritualidade. 4. Ed. Rio de Janeiro: Rocco, 1994.

CONFERÊNCIA NACIONAL DOS BISPOS DO BRASIL, Campanha da Fraternidade 1998, Fraternidade e Educação - A serviço da vida e da esperança, TEXTO-BASE, 2. ed. São Paulo: Salesiana Dom Bosco, n 89. 
DELORS, Jacques. La educación o la utopía necesaria. in: La educación encierra un tesoro - Informe a la UNESCO de la comisión Internacional sobre la educación para el siglo XXI, presidida por JACQUES DELORS, Santillana Ediciones UNESCO, 1996. p.18.

GADOTTI, Moacir; FREIRE, Paulo; GUIMARÃES, Sérgio. Pedagogia: diálogo e conflito. 4 ed. - São Paulo: Cortez, 1995.

GALLO, Silvio. Disciplinaridade e transversalidade. In. Linguagens, espaços e tempos no ensinar e aprender. Unicamp e Unimep, 2000.

IAMMARRONE, Giovanni. L'uomo immagine di Dio - Antropologia e Cristologia. Roma: Borla, 1989.

LADARIA, Luiz F. Introduzione all'Antropologia Teologica. 7. ed, 8 IDT, Roma: Ed. Piemme, 1997.

NANZHAO, Zhou. Las interacciones entre la educación y la cultura con miras al desarrollo económico y humano: un punto de vista asiático. in: La educación encierra un tesoro Informe a la UNESCO de la comisión Internacional sobre la educación para el siglo XXI, presidida por JACQUES DELORS, Santillana Ediciones UNESCO, 1996.

Pontifício Conselho para o Diálogo Inter-Religioso: Diálogo e Anúncio. São Paulo: Paulinas, 1996.

PAPA FRANCISCO. Carta enc. Laudato Sí. (24 de maio de 2015).

ROCHA, Everardo P. Guimarães. O que é Etnocentrismo. 11. Ed São Paulo:Brasiliense. SINGH, Karan. Educar para la sociedad mundial. in: La educación encierra un tesoro - Informe a la UNESCO de la comisión Internacional sobre la educación para el siglo XXI, presidida por JACQUES DELORS, Santillana Ediciones UNESCO, 1996. 